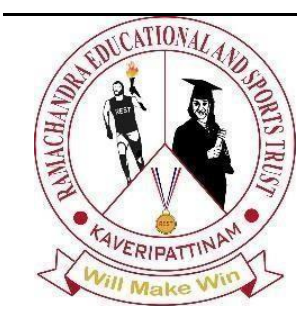

REST Journal on Emerging trends in Modelling and Manufacturing

Vol: 6(4), 2020

REST Publisher

ISSN: 2455-4537

Website: www.restpublisher.com/journals/jemm

\author{
Design of Bio Mimic Impeller \\ Prashant Chalise, Jeevan Kittur \\ Mukesh Patel School of Technology Management and Engineering, Shirpur
}

\begin{abstract}
Biomimicry is learning from nature and then emulating nature's forms, processes, and ecosystems to create more sustainable designs. The concept of biomimicry is based on a key idea: nature always operates on the principles of economy and efficiency while generating no waste. Biomimicry is needed in today's world because designers are innately curious, and biomimicry provides the opportunity to learn about life's complex processes and strategies, broadening the design space and bringing new solutions to the table. In this project I am going to combine the biomimicry used in Lily Impeller which is inspired by the shape of calla lily flower and based on the logarithmic curve (known as the Fibonacci spiral) found in nautilus shells, it's function is similar to that of whirlpools but with slight difference and the biomimicry of Humpback Whale which is the Tubercles on its flippers, together designed to develop a new impeller with possibly higher efficiency than the existing impellers in the market. The new impeller has function similar to that of whirlpool but with slight difference, an ideal whirlpool generates centrifugal force outwards from the center of rotation whereas the new impeller generates centrifugal force towards the center of rotation this result is the reduction or elimination of drag and resistance. It has a number of sinusoid-like bumps similar to tubercles, which are arranged periodically along the leading edge. The presence of these bumps modifies the water flow over the surface, creating regions of vortex generation between the bumps. These vortices interact with the flow of water over the bumps and accelerate that flow, helping to maintain a partially attached boundary layer. This hydrodynamic effect can delay stall to higher angles of attack, increases lift, and reduces drag. In this research paper I have done solid modelling using Solid works software.
\end{abstract}

Keywords: Biomimicry, whirlpools, tubercles, drag, resistance, angles of attack.

\title{
1.Introduction Motivation:
}

In mixing water storage tanks stagnation occurs when water is poorly mixed or inadequately circulated, often due to the mismatch between tank size and daily demand. Tanks can be ten or more times larger than daily demand in order to meet future projected demand and fire/emergency capacity. This overcapacity is particularly exaggerated in new developments with incomplete residency, and therefore insufficient daily turnover of stored water. Additionally, thermal loading by sunlight and ambient air results in temperature stratification-the vertical separation of water with varying temperatures. This condition prevents natural mixing, as new, colder water slides under the older, warmer water. Stratification only requires 0.1 -degree Celsius temperature differential. The older, warmer water at the top loses its disinfectant capacity and can experience bacterial and microbial growth. Chemical treatment, aside from being associated with potential safety issues, has been unsuccessful in preventing stratification and stagnation. The last of developments made in this field to solve this problem was that of lily impeller back in 2006, since then as we are aware that there have been many technological advancements in every field also Conventional fluid dynamics holds that the the leading edge of the impeller should be smooth but research has found that the humpback whale flipper have a number of sinusoid-like rounded bumps, called tubercles, which are arranged periodically along the leading edge this increases angles of attack, increases lift, and reduces drag compared to the post-stall condition of conventional wings. So, I wanted to design and upgrade the current model used in this area. So that we can achieve better results as per current scenario.

\begin{tabular}{|c|l|l|l|}
\hline Sr. No & \multicolumn{1}{|c|}{ Author } & \multicolumn{1}{|c|}{ Work Done } & \multicolumn{1}{c|}{ Remarks } \\
\hline 1 & $\begin{array}{l}\text { Barbero, Silvia; } \\
\text { Pallaro, Agnese }\end{array}$ & $\begin{array}{l}\text { Analysis of how the } \\
\text { changing relation between } \\
\text { man and water in history has } \\
\text { been translated in the design } \\
\text { of different kinds of tools } \\
\text { for water management. }\end{array}$ & $\begin{array}{l}\text { The Systemic Design approach shares the vision of nature } \\
\text { efficiency available. In relation to the topic of water the } \\
\text { design process is based on the detailed analysis of the } \\
\text { behaviour and properties of water with the aim to build } \\
\text { tools that are truly sustainable. }\end{array}$ \\
\hline
\end{tabular}




\begin{tabular}{|c|c|c|c|}
\hline 2 & $\begin{array}{l}\text { Fish, Frank E., } \\
\text { Paul W. Weber, } \\
\text { Mark M. Murray, } \\
\text { and Laurens E. } \\
\text { Howle }\end{array}$ & $\begin{array}{l}\text { The Tubercles on Humpback } \\
\text { Whales' } \\
\text { Flippers: Application of } \\
\text { Bio-Inspired Technology. }\end{array}$ & $\begin{array}{l}\mathrm{k} \text { The tubercles on the leading edge act as passive-flow } \\
\text { control devices that improve performance and } \\
\text { maneuverability of the flipper. Experimental analysis of } \\
\text { finite wing models has demonstrated that the presence of } \\
\text { tubercles produces a delay in the angle of attack until stall, } \\
\text { thereby increasing maximum lift and decreasing drag. }\end{array}$ \\
\hline 3 & $\begin{array}{l}\text { Norbert Hoeller, } \\
\text { Margo } \\
\text { Farnsworth, } \\
\text { Shoshanah } \\
\text { Jacobs, Filippo } \\
\text { Arnaldo Salustri }\end{array}$ & $\begin{array}{l}\text { A Systems } \quad \text { View of } \\
\text { Bioinspiration: } \quad \text { Bridging } \\
\text { the Gaps. }\end{array}$ & $\begin{array}{l}\text { The paper explores three levels of biomimicry bridging, } \\
\text { discusses benefits and implications of adopting a systems } \\
\text { perspective, and proposes initiatives for further } \\
\text { development. Searching for 'sweet spots' leveraging the } \\
\text { synergy between our aspirations, our growing knowledge } \\
\text { of natural systems, and the market economy will improve } \\
\text { the ability of biomimicry to deliver meaningful and } \\
\text { impactful solutions. }\end{array}$ \\
\hline 4 & $\begin{array}{l}\text { Weichao Shi, } \\
\text { Mehmet Atlar, } \\
\text { Rosemary } \\
\text { Norman }\end{array}$ & $\begin{array}{l}\text { Learning from Humpback } \\
\text { Whales for Improving the } \\
\text { Energy Capturing } \\
\text { Performance of Tidal } \\
\text { Turbine Blades. }\end{array}$ & $\begin{array}{l}\text { This paper summarizes a project on the potential of further } \\
\text { improving the performance of horizontal axis tidal } \\
\text { turbines via the application of leading-edge tubercles to } \\
\text { the turbine blades inspired by humpback whales. Within } \\
\text { this framework, a wide variety of experimental } \\
\text { investigations, supported by numerical studies, have been } \\
\text { conducted. }\end{array}$ \\
\hline 5 & $\begin{array}{l}\text { Siobhan Watson, } \\
\text { Chris Garvin, and } \\
\text { Namita } \\
\text { Kallianpurkar, } \\
\text { Terrapin Bright } \\
\text { Green }\end{array}$ & $\begin{array}{l}\text { Biomimicry in New York } \\
\text { State. }\end{array}$ & $\begin{array}{l}\text { Biomimicry is both a methodology and a design mindset } \\
\text { that helps identify and solve problems in areas such as } \\
\text { energy performance, efficient use of water, toxin } \\
\text { reduction, and waste elimination. It helps point the way to } \\
\text { advancements that are essential to ensuring the longterm } \\
\text { competitive success of NYS companies. }\end{array}$ \\
\hline 6 & $\begin{array}{l}\text { Kamran } \\
\text { Mahmudov }\end{array}$ & 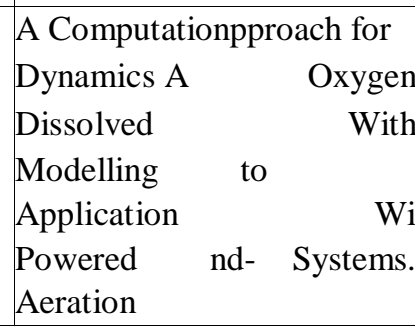 & $\begin{array}{l}\text { The main contribution of this thesis was the development } \\
\text { of a computational model that can predict spatial and } \\
\text { temporal distribution of dissolved oxygen concentration in } \\
\text { water bodies. The model enables the design and optimize } \\
\text { ierations technologies to have higher efficacy. }\end{array}$ \\
\hline 7 & $\begin{array}{l}\text { Weichao Shi, } \\
\text { Mehmet Atlar, } \\
\text { Rosemary } \\
\text { Norman, } \\
\text { Batuhan Aktas, } \\
\text { Serkan Turkmen }\end{array}$ & $\begin{array}{l}\text { Biomimetic improvement } \\
\text { for a tidal turbine blade }\end{array}$ & $\begin{array}{l}\text { This paper is to investigate the leading-edge tubercle of } \\
\text { humpback whale fins to be apply on a hydrofoil which is } \\
\text { based upon a tidal turbine blade by using computational } \\
\text { and experimental approaches. }\end{array}$ \\
\hline
\end{tabular}
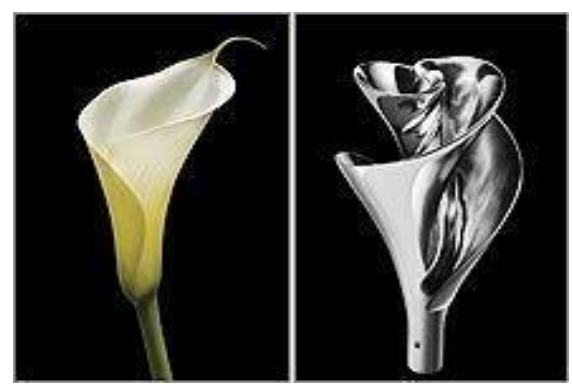

Figure 1

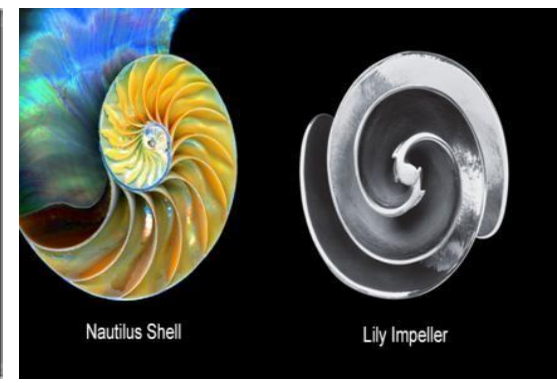

Figure 2

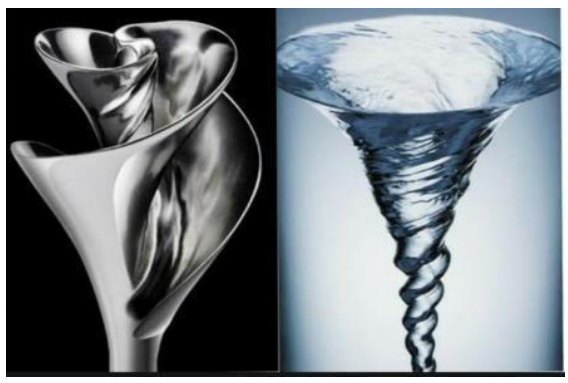

Figure 3 


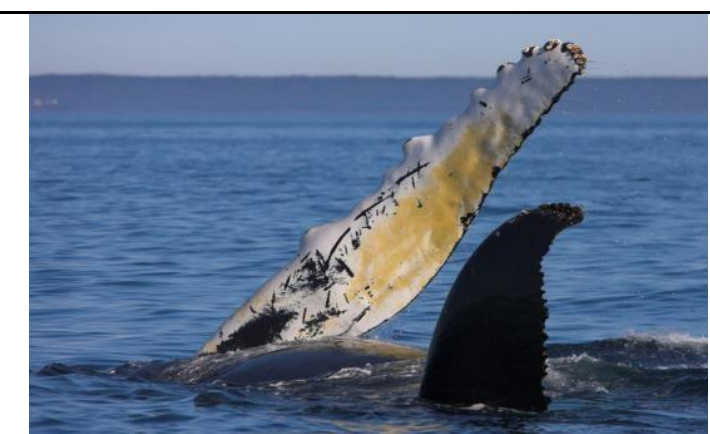

Figure 4

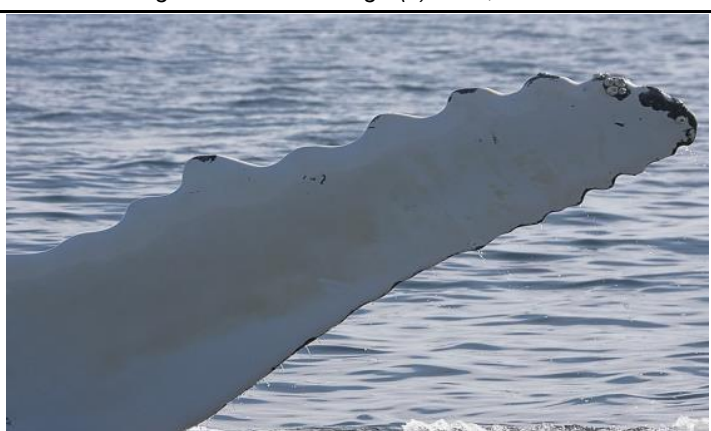

Figure 5

\section{Literature Review}

The review has been carried out for the project work by referring to the previous work done in this filed and future development.

\section{Methodology}

Literature review: Different research papers, journals, thesis and articles are reviewed to get better understanding of the topic. Solid modelling: Modeling is done on Solid works software. Comparative Study. 4.Result and Discussion

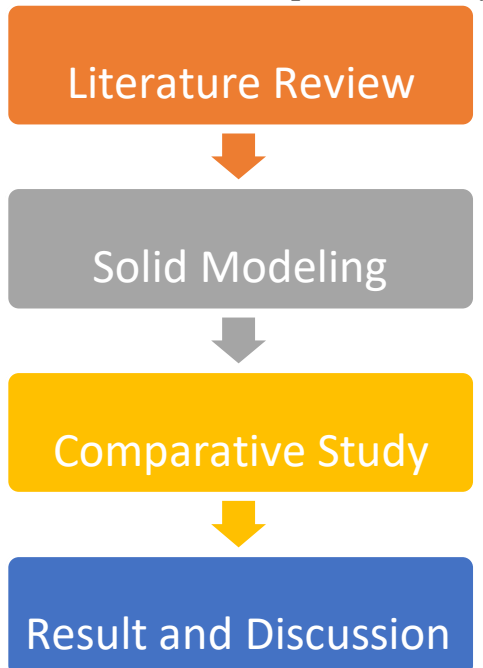

Figure 6

Solid works software is used for modeling.

\section{Software Model}

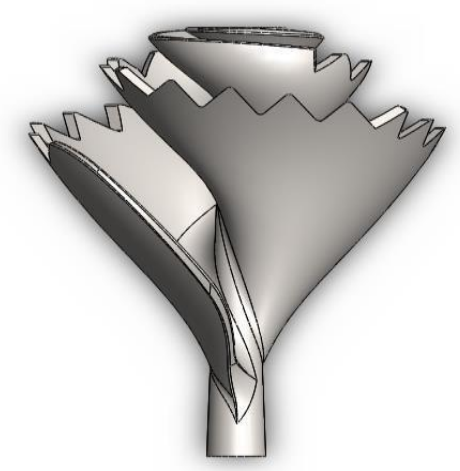

Figure 7

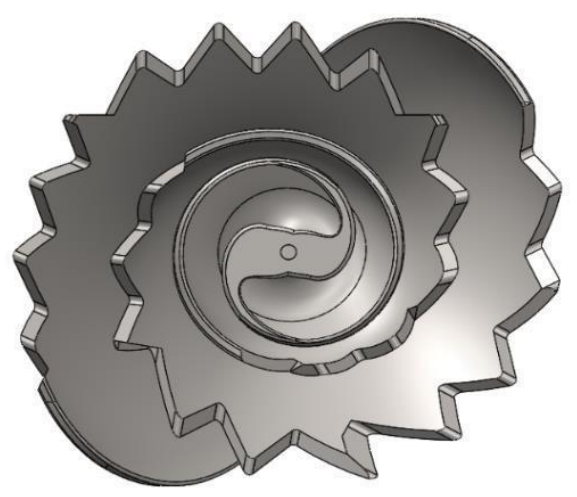

Figure 8 


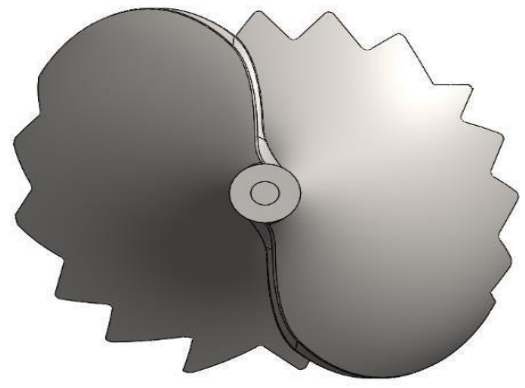

Figure 9

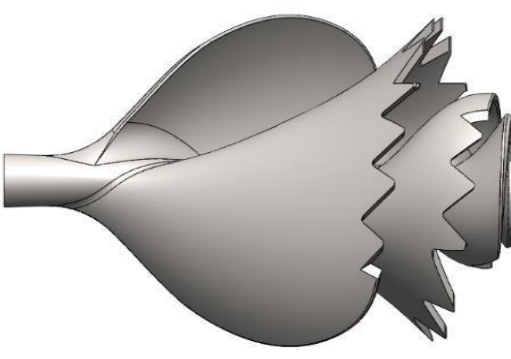

Figure 10

In this project the new impeller design was achieved by studying various resources available online such as research papers, journals, thesis and articles. All these resources helped me in the better understanding of different types of impellers used in mixing water storage tank, the concept of biomimicry and how biomimicry helps us to design existing technology in much efficient way.

\section{Conclusion}

This project has helped in achieving new design of a impeller by combing biomimicry used in Lily Impeller which is inspired by the shape of calla lily flower and based on the logarithmic curve (known as the Fibonacci spiral) found in nautilus shells, it's function is similar to that of whirlpools but with slight difference and the biomimicry of Humpback Whale which is the Tubercles on its flippers, together designed to develop a new impeller with possibly higher efficiency than the existing impellers in the market. The new impeller has function similar to that of whirlpool but with slight difference, an ideal whirlpool generates centrifugal force outwards from the center of rotation whereas the new impeller generates centrifugal force towards the center of rotation this result is the reduction or elimination of drag and resistance. It has a number of sinusoid-like bumps similar to tubercles, which are arranged periodically along the leading edge. The presence of these bumps modifies the water flow over the surface, creating regions of vortex generation between the bumps. These vortices interact with the flow of water over the bumps and accelerate that flow, helping to maintain a partially attached boundary layer. This hydrodynamic effect can delay stall to higher angles of attack, increases lift, and reduces drag. The expected results from this project are:

1)Increase in efficiency of impeller.

2)Reduction in drag.

3)Improve performance of impeller.

\section{Reference Bibliography}

[1]Mahmudov, K., Mahmoud, A., Sur, S., Cruz, F.C. and Bilton, A.M., 2019. Feasibility of a wind-powered aeration system for small-scale aquaculture in developing countries. Energy for Sustainable Development, 51, pp.40-49.

[2]Mahmudov, K., 2019. A Computational Fluid Dynamics Approach for Dissolved Oxygen Modelling with Application to Wind-Powered Aeration Systems (Doctoral dissertation).

[3]Dev Anand, K. A. Janardhanan, R. Rajesh, Ramachandran. M, Fibre Reinforced Plastic Material with Aluminum Filling Used for Ship Superstructure, Journal of Chemical and Pharmaceutical Sciences 9(1):351-355 • May 2016.

[4]Grover, S., 2013. The Lily Impeller: Nature-based design inspires game-changing efficiencies. Mother Nature Network. Retrieved January 21, p.2016.

[5]Watson, S., Garvin, C., Kallianpurkar, N. and Green, T.B., Biomimicry in New York State.

[6]Weidner, B.V., Nagel, J. and Weber, H.J., 2018. Facilitation method for the translation of biological systems to technical design solutions. International Journal of Design Creativity and Innovation, 6(3-4), pp.211-234.

[7]Schneider, S., 2016. Naturally Synthetic: Our Interwoven World (Doctoral dissertation).

[8]Isaacs, A.M. and Koelman, O., 2006. PAX scientific. The Berkeley-Haas Case Series. University of California, Berkeley.

Haas School of Business.

[9]Schroeter, D.L., 2010. Introducing biomimicry. Green Teacher, (88), p.13.

[10]Hoeller, N., Farnsworth, M., Jacobs, S., Chirazi, J., Mead, T., Goel, A. and Salustri, F., 2016. A Systems View of Bioinspiration: Bridging the Gaps. INSIGHT, 19(1), pp.36-40.

[11]Wang, J., Nakata, T. and Liu, H., 2019. Development of Mixed Flow Fans with Bio-Inspired Grooves. Biomimetics, 4(4), p.72.

[12]Yugal Bagrecha, Raj Tailor, M. Ramachandran, P. Raichurkar, An effect of banana fiber size on banana fiber reinforced epoxy composites with coconut shell powder as filler, International Journal of Mechanical and Production Engineering Research and Development, 2018, December, 150-155.

[13]Anderson, D., Mishra, B. and Fergus, J., 2015. Engineering and Producing a Sustainable Material Supply: Challenges and Opportunities. In Engineering Solutions for Sustainability (pp. 3-22). Springer, Cham.

[14]Fry, B., Fry, C.B., Lehni, J., Franke, U., cantonale d'art de Lausanne, É., Hoberman, C., Lang, R.J., Patterns, O.C. and Lang, C.R.J., 0 INTRO.

[15]Barbero, S. and Pallaro, A., 2020. Relation between man and water. 
[16]Moore, R.L., 2011. A Sustainable Approach to Managing Potable Water Quality. Journal of the New England Water Works Association, 125(3), p.255.

[17]Anupama Rajput, Pradip Jamadar, M. Ramachandran, Vishal Fegade, Characterization of Banana Fiber Reinforced with PLA Composites and its Effect on Copper Nano Powder, International Journal of Mechanical and Production Engineering Research and Development, 2018, August, 42-50.

[18]Fish, F.E., 2009, August. Biomimetics: determining engineering opportunities from nature. In Biomimetics and Bioinspiration (Vol. 7401, p. 740109). International Society for Optics and Photonics.

[19]Ibrahim, I.H. and New, T.H., 2015, June. Tubercle modifications in marine propeller blades. In 10th Pacific symposium on flow visualization and image processing. Naples, Italy (pp. 15-18).

[20]Shi, Weichao, Mehmet Atlar, Rosemary Norman, Batuhan Aktas, and Serkan Turkmen. "Biomimetic improvement for a tidal turbine blade." In 11th European Wave and Tidal Energy Conference, pp. 110-119. 2015.

[21]Vaithiyanathan, D., R. Seshasayanan, S. Anith, and K. Kunaraj. "A low-complexity DCT approximation for image compression with 14 additions only." In 2013 International Conference on Green Computing, Communication and Conservation of Energy (ICGCE), pp. 303-307. IEEE, 2013.

[22]Hariharasakthisudhan, Ponnarengan, Swaminathan Jose, and Kondal Manisekar. "Dry sliding wear behaviour of single and dual ceramic reinforcements premixed with Al powder in AA6061 matrix." Journal of Materials Research and Technology 8, no. 1 (2019): 275-283. 